\title{
Approach to Effective Practice Strategies in Music David Benders
}

\author{
David Benders \\ Union College \\ *Corresponding author: dbenders@unionky.edu
}

Copyright (C) 2013 Horizon Research Publishing All rights reserved.

\begin{abstract}
The practice of practicing music should be a meaningful experience that produces musicians with a lifelong love of music. The use an organized practice system that includes goal setting, specific practice strategies, self and teacher assessment, and the development of intrinsic motivation, lays a foundation for musical success. In the classroom, teachers model efficient practice techniques and establish classroom routines that encourage cooperation, and reward individual progress instead of competition. Evidence provided by research demonstrates the need of teachers to abandon the practice of "time served" and recorded, to training young musicians to systematically practice.
\end{abstract}

Keywords Practice, Self-Efficacy, Goals, Assessment, Strategies, Motivation, Intrinsic, Extrinsic, Leadership, Supervision, Memory Persistence, Aural Image

\section{Introduction}

The necessary evil known as practice is familiar and accepted by all musicians. Repetition is the standard part of developing and refining music skills (Duke, 2011). Beginners to professionals need to rehearse to learn and improve musical performance.The most common teaching practice in public schools is to require practice records, which are essentially time logs. Grades assigned from these logs range from a minor percentage to significantly impacting student's grades. Grades used as a reward to students does not motivating students to practice(Smeltz, 2012).Research in this area is providing new direction and needed change in defining and teaching students to practice. Townsend (2012) suggests the following acrostic as a starting point in redefining practice.Preparing Relevant Activities Causes Technical Improvement and Correct Execution.(PRACTICE)The focus of this acrostic is to think systematically about the why and how of practice. While musical practice is equivalent to homework, if classroom teachers who simply assigned thirty minutes of math practice without any specific assignment, would experience the same results as music teachers. While recording simple time sheets is a simple way of assigning a grade, ultimately it makes no difference musically and is a complete waste of time and effort.

"A key goal for music teachers is to develop literate musicians who no longer need us.For this to occur, they must become independent learners."(Oare, 2011)The goal of producing self-directed musical practice involves:

-Set clear, measurable, timely goals;

-Plan and create effective strategies;

-Self-monitor and adjust;

- Structure optimal learning environments;

-Seek out advice and information; and

-Display consistent effort and persistence.(Oare, 2011)

Teachers who provide this structure and equip students with a toolbox of guided practice sheets and specific practice tools continue to see improvement and create a higher percentage of students who experience lifelong love of music and are intrinsically motivated.

\section{Discussion of Key Terms}

Practice is the process of learning through systematic experience or exercise targeting specific goals (Austin \& Berg, 2006 as cited in Schatt, 2011). It involves character qualities such as dedication, commitment, and perseverance, which are non-musical traits but essential elements of successful people.Practice is also an important predictor of music achievement(e.g., Ericsson, Krampe, \&TeschRomer, 1993; Miksza, 2007: Sloboda, Davidson, Howe, \& Moore, 1996 as cited in Schatt, 2011). To achieve musical excellence it is generally accepted and understood that a musician will need to spend time practicing.To practice well a musician must be dedicated to practice but time alone is not the key to real success.Research suggested successful musicians' are maximizing their practice time to be more productive compared to watching the clock and practicing long hours(Pitts, Davidson, \& McPherson, 2000, as cited in Christensen, 2010).

As it pertains to music, the ability to self-regulate requires 
knowledge that time spent in practice of playing or singing alone will not provide.Knowledge that produces regulation needs aural image of the music being prepared, strategies to improve, and authentic assessment.When a musician is aware of the goal (aural image), is able to identify what needs to improve, and has tools to fix or build the performance (strategies to improve), and can provide formative assessment intended to demonstrate progress as well as identify areas needing improvement.Essential to this process is the concept of memory-persistence.Music students should have a similar student lead instructional approach as they do in their core learning classes. The opportunity to identify and correct their mistakes is a good learning tool(Duke, 2012).Time is essential to improvement, but the time invested needs structure, effective strategies for improvement, and assessment that informs.

Goals, motivation, leadership, supervision address the intrinsic and extrinsic component musicians utilize to stay focused and continue to progress.Musicians exert effort and energy, spend their time, apply strategies, and utilize feedback.They must possess intrinsic motivation produced through self-efficacy;and extrinsic motivation shaped through assessment from supervision in the form of verbal feedback and written forms such as guided practice records."Practice sheets, check-off sheets, and performance rubrics are especially useful for teaching these skills."(Oare, 2011)By applying a systematic approach to practice, they are able to achieve their personal goals as well as challenges presented by teachers. The capacity to respond to leadership via assessment and to provide their own leadership through goal setting is essential for pushing through difficulty and continuing to pursue musical excellence."... it appears that teachers can improve student motivation by providing students goals for improvement rather than simply recording practice time."(Oare, 2012)

\section{Review of Literature}

Green and Hale (2011) emphasize the use of challenging, meaningful tasks, evaluation and recognition practices emphasizing effort and enjoyment, and encouraging students by involving decision input and choice.Oare (2012) arrives at similar conclusions when he states, "it may be more effective to place a focus on personal improvement by assessing student progress toward periodic goals or by asking student to self-assess their progress toward their own daily or weekly goals (Oare, 2012)." In the same study,Oare encourages teachers to set proximal and moderately challenging goals and utilize appropriate strategies in order to achieve these goals.Miksza (2012) conceptualize students' self-sufficiency in terms of the social-cognitive theory of self-regulation. Three dimensions of self-regulated learning are method, behavior, and time use.By comparison to Green and Hale (2011) and Oare (2012), a method is the combination of challenging, meaningful tasks, focused on personal improvement.Behavior connects to evaluation and self-assessment which guides the use of strategies designed to change behavior.

Christensen (2010) concluded that students efficacy or self-regulation were important factors that effected students personal enjoyment.Students who experienced enjoyment when practicing possessed strategies for improving.Smeltz(2012) states, “...through direct instruction in practice strategies, eliminating practicing grades and time requirements, and leading by example, we can help students achieve a high level of performance and lay the foundation for a lifetime of musical participation and enjoyment."Duke (2012) makes a case for creating memory-persistence by allowing students to work hard enough to actually create lasting change in the learner's memory.Proposing a similar approach to muscle memory for athletes, the learner's memory provided a greater learning curve for the student. Mistakes are an essential part of learning, but what renders the mistakes useful is the corrections by the learner.Working through muddles, then, produces intellectual, physical, and emotional positives are simply not attainable in any other way.Practice that provide scaffolding for the learner without doing it for them, builds confidence and allows the learner/musician to take risks without fear of failure.Schatt (2011) emphasizes the importance of making practice scheme the "play-full" element of music.Applying goal orientation theory organizes the goal, the drive, and the reasons for engaging in various achievement tasks during practiceSchatt (2011). When students are competing for a grade or a chair, the play becomes work, and the satisfaction becomes recognition for earning a grade or chair.Once achieved, rather than continuing to practice for the joy of improving or personal accomplishment, practice is set aside until the next goal is set.

The use of guided practice records, rubrics, targeted practice guides, etc. is a tool that helps young musicians use strategies without fully understanding why the technique or strategy should or does work.Johnson (2009) created several such paper assistants to develop effective practices.Anticipating the potential musical difficulties, he designed these practice records with strategies to meet the needs of the student.Items targeted by such practice records were:

\section{- Goals \\ -Strategies \\ -Reflection or Self-evaluation \\ -Problem solving \\ -Instructor feedback}

Townsends (2012) acrostic, PRACTICE, is similarly designed to help more advanced students think systematically and apply previous knowledge vs. establish new knowledge.Oares (2011) Self-Regulated Practice Model involves a process of supervised motivation/goals with an aural image of the music being rehearsed, along with assessment and strategies for improvement. 


\section{Conclusion/Summary}

Student needs and development levels are paramount in creating an effective and efficient practice approach to learning music. Considering students' needs and developmental levels when creating practice assignment that methodically lead our students toward becoming self-regulated learners.By being intentional about practice education as we are with other aspects of music education, we can teach student to practice effectively.Music educators must give serious and thoughtful consideration to the practice of practice. There is much that students can and should learn when practicing however, students must ultimately experience the "thrill of victory" without feeling "pardoned" for "time served."A systematic approach that sets developmentally appropriate goals, provides specific strategies to address anticipated needs, includes assessment feedback for improvement. Consequently, the learner will provide a solid foundation to a life-long love of musical study.

\section{REFERENCES}

[1] Christensen, S., (2010, November) Practicing strategically: the difference between knowledgeand action in two eighth-grade students' independent instrumental practice, Research in music education, Vol. 29, no. 1, 22-32, doi: $10.1177 / 8755123310377924$

[2] Duke, R. A. (2012).Their Own Best Teachers: How We Help and Hinder the Development of Learners' Independence.Music Educators Journal, 99(2), 36-41.doi:10.1177/0027432112458956
[3] Green, S. K., \& Hale, C. L. (2011).Fostering a Lifelong Love of Music: Instruction andAssessment Practices that Make a Difference.Music Educators Journal, 98(1), 45-50.doi:10.1177/0027432111412829

[4] Johnson, D., (2009, March) More than just minutes: using practice charts as tools for learning,Music Educators Journal, Vol. 95, No. 3, 63-70, http://www.jstor.org/stable/30219217

[5] Miksza, P., Prichard, S., and Sorbo, D., (2012, October) An observational study of intermediateband students' self-regulated practice behaviors, Journal of Research in Music Education, vol. 60, no. 3, 254-266, doi: $10.1177 / 0022429412455201$

[6] Oare, S. (2012).Decisions Made in the Practice Room: A Qualitative Study of Middle School Students' Thought Processes While Practicing.Update: Applications of Research in Music Education, 30(2), 63-70.doi:10.1177/8755123312437051

[7] Oare, S. (2011).Practice Education: Teaching Instrumentalists to Practice Effectively.Music Educators Journal, 97(3), 41-47.doi:10.1177/0027432111400006

[8] Schatt, M. D. (2011).High School Instrumental Music Students' Attitudes and Beliefs Regarding Practice: An Application of Attribution Theory.Update: Applications of Research in Music Education, 29(2), 29-40.doi:10.1177/8755123310396981

[9] Smeltz, H. (2012).Reframing Student Practice to Facilitate Lifelong, Joyful Musicianship.Music Educators Journal, 99(2), 51-55.doi:10.1177/0027432112463248

Townsend, B. (2012, November) Understanding PRACTICE: an acronym for the holisticapproach to practice, International Journal of Music Education,vol. 30 no. 4 397-408, doi: $10.1177 / 0255761412459168$ 